\title{
LUSOPHONE GEOPOLITICAL SPACE: VIDAS EM PORTUGUÊS
}

\author{
Regina Brito
}

\begin{abstract}
Língua - vidas em Português (2004), by Victor Lopes, shows the presence of Portuguese culture and language from around the world; the basis of representation of the lusophone universe are Goa, Mozambique, Brazil, Portugal, and Japan. Our work stems from the hypothesis that opinions, feelings, practices and behaviors manifested in Portuguese by common individuals present in the documentary can indicate significant elements for the comprehension of Lusophony. It is by the social spaces they occupy that their speech can be taken as a way of life, which encompasses opinions of the Portuguese language and representations of the culture they belong to, emphasizing relations between local meanings and those originating from abroad. Finding the balance between the local and global, just as the historic tensions among values (tradition in opposition to innovation, for example) of the lusophone universe are consequences of the analysis that the documentary bequeaths us as significant. As such, from this discursive manifestation, other lines of thinking the lusophone concept emerges through a reading key that neutralizes or complexifies oppositions, constructing the representation of Lusophony as a space marked by the meeting of differences, not necessarily in competition with each other, but rather, a supranational space in permanent dialogue.
\end{abstract}

KEYwORDS

Lusophone Studies; lusophone identity; Portuguese in the world

\section{EspaÇo geopolítico lusófono: VIDAS em PoRtuguês}

\begin{abstract}
Resumo
Língua - vidas em Português (2004), de Victor Lopes, mostra a presença da cultura e da língua portuguesa em diferentes partes do mundo, tomando como representação do universo lusófono: Goa, Moçambique, Brasil, Portugal e Japão. Nosso trabalho parte da hipótese de que opiniões, sentimentos, práticas e comportamentos manifestados em Português por indivíduos comuns presentes no documentário indiciam elementos significativos para uma compreensão de lusofonia. Pelo lugar social que ocupam, suas falas são tomadas como estilos de vida englobantes de opiniões sobre a língua portuguesa e representações da cultura à qual pertencem, enfatizando relações entre os sentidos locais e as significações advindas de fora do país. Encontrar o ponto de equilíbrio entre o local e o global, assim como as tensões históricas entre valores (tradição em oposição à inovação, por exemplo) do universo lusófono são consequências da análise a partir do que o documentário nos lega enquanto significação. Assim, por essa manifestação discursiva, outras linhas de entendimento de lusofonia podem surgir por meio de uma chave de leitura que neutraliza ou complexifica as oposições, construindo uma representação de lusofonia como um espaço marcado pelo encontro de diferenças que não necessariamente estão em competição, mas, ao contrário, como um lugar supranacional em permanente diálogo.
\end{abstract}

PaLAVRas-chave

Estudos Lusófonos; identidade lusófona; Português no mundo 
At a certain point, Portuguese lost its owner. Mia Couto (Língua - vidas em Português, 2004)

\section{GLOBALIZED SPACES AND LUSOPHONY}

The epigraph which opens this article, extracted from the documentary Língua vidas em Português (also referred in the title), was the motto which guided, in this work, the reflections regarding the Lusophone Studies. We start off from the considerations on the globalized space and its relation for the construction of an idea of Lusophony, to, in sequence, bring up the testimonials of some of the "lives in Portuguese" taken from the documentary.

Understanding the "globalized space" implicates: our living the accelerated development of the communication systems and with it the reduction of distances and time (Harvey's time-space compression, or Bauman's ${ }^{2}$ suppression of the time-space barriers); our witnessing the advancement of digital media, narrowing the limits between privacy and self-publication; our seeing the emerging of new economic blocks to integrate markets (but not, necessarily, people); our observing the rapid dissemination of information of almost any nature (Castells'3 informational society).

However, capitalist society does not seem to suffer setbacks from these movements that assist in the characterization of the global space because the massified culture continues to superimpose on the local ones. In this scenario, globalization appears as a process which seeks to nullify difference, imposing a dominating culture; in other words, it is a process which standardizes everything and tends to eliminate the unique. To an extent, Lusophony could be a resistance that feeds exactly off the appreciation and reconstitution of local ways and values.

Globalization, meanwhile, does not occur irregularly, for a reaction to the homogenization process is underway, in which local production of culture is put against globalization and the cultural industry, fortifying its local elements. Therefore, globalization in contemporaneity faced the resurging of the reaffirmation of individual identities (ethnic, regional, sexual, of gender, etc.), and, naturally, the very notion of identity, which solidified with the ascension of nations and went through transformations because of these new times:

\footnotetext{
1 "As space appears to shrink to a 'global village' of telecommunications and a 'spaceship earth' of economic and ecological interdependencies... and as time horizons shorten to the point, where the present is all there is... we have to learn how to cope with an overwhelming sense of compression of our spatial and temporal worlds" (Harvey, 1989, p. 240).

2 "The change in question is the new irrelevance of space, masquerading as the annihilation of time. (...) space may be traversed, literally, in 'no time'; the difference between 'far away' and 'down here' is cancelled. Space no more sets limits to action and its effects, and counts little, or does not count at all” (Bauman, 2000, p. 117).

3 "In the new, informational mode of development the source of productivity lies in the technology of knowledge generation, information processing, and symbol communication. (...) in a virtuous circle of interaction between the knowledge sources of technology and the application of technology to improve knowledge generation and information processing" (Castells, 2010, p. 17).
} 
globalization, however, produces different outcomes for identity. The cultural homogeneity promoted by global marketing could lead to the detachment of identity from community and place (...) This dispersal of people across the globe produces identities which are shaped and locates in and by different places. (Woodward, 1997, pp. 16-17)

Against that background, a new representation of Lusophony emerges from the processes of independence in the $1970 \mathrm{~s}^{4}$. At first, Lusophony is understood as a connection, in the institutional level, of the countries which assumed Portuguese constitutionally as official. Consequently, the Portuguese inheritance remained as the basis for this melting-pot of cultures of these countries; thus, in a way, reflecting on a viable Lusophony (Brito, 2017) supposes the establishment or reestablishment of historical and cultural ties between countries in different parts of the globe, originating from a common element - the Portuguese language - which, necessarily, has distinctive norms in each location. Apart from this linguistic bond, a meaningful Lusophony should stem from the intricacies of the cultural relations that make up those who are part of it, as pointed out by Martins (2006, p. 58):

Lusophony can only be understood as a culture space. And as a culture space, Lusophony cannot stop reminding us of that which can be called the fundamental indicator of anthropological reality, in other words, to the indicator of humanization, which is within the imaginary realm of landscapes, tradition and language, that claim Lusophony, and that is finally the territory of the cultural archetypes, a collective lusophone unconscious, a mythical background of which dreams are fed.

There are, however, those who view Lusophony as an empty project with problematic application because, specifically, of the multiplicity of discourses and definitions (or indefinitions) of the denominated lusophone universe. If there are authors who identify a certain fragility of the lusophone project, there are others who defend the balance amidst the discursive multiplicity, mainly because of the need of recognition for the relation between the linguistic-cultural diversity and unity. For example, Cunha (2012, p 260) proposes a comprehension of Lusophony as a "point of convergence of distinct and dispersed social identities" Since this author intends to study Lusophony in the scope of the relations between identity and culture, his purpose is to try and overcome the linguistic dimension of this issue without, however, denying it in order to use it as complementary - and not as a final point - of such discussion. Along the same lines,

the Lusophony that takes on the qualities of 'viable', of 'possible', of 'admissible' should have its identity constructed in a continuous dynamic of respect, knowledge, recognition and legitimacy one for another, in which

\footnotetext{
${ }_{4}$ We refer, here, to the countries colonized by Portugal whose Independence occurred between 1974 and 1975, after the Carnation Revolution: Angola, Cape Verde, Guinea-Bissau, Mozambique, Saint Thomas and Principe (in Africa), and East Timor (in Asia).
} 
we will point out the differences and affinities. A Lusophony can only be 'legitimate' insofar as it recognizes the different roles the Portuguese language takes on in each place, constructs itself through the evocation of various sounds and accents and, also, points to a conceptualization that is disconnected from self-centeredness and/or discomforts that the word LUSOPHONY may at times carry, in retrograde discourses, because of its identifying with a centrality of the Portuguese matrix in relation to the other countries of the CPLP (Community of Portuguese Language Countries), which does not make sense. An "authentic" Lusophony has no center, but centers everywhere. (Brito, 2017, p. 1045)

Lusophony projects itself, therefore, as a space for the conciliation of linguistic (in relation to the varieties of the Portuguese language and to the national/local languages) and cultural (with different trajectories and social-cultural practices, standards, experiences, etc.) diversity through the unity of Portuguese. For this reason, it is fundamental to recognize, defend and legitimize the right of coexistence of the various norms and standards of Portuguese in all the lusophone spaces, as well as the existing national languages, based on the principle of "integration between unity/variety" (Brito, 2013, pp. 57-59), capable of bringing meaning to the edification of a lusophone atmosphere

We understand that the symbolic space ${ }^{5}$, in which Lusophony is constituted, cannot involve only rationally articulated meanings, but should also encompass memories, traditions, habits and values which overextend and constitute each of the countries of the CPLP and the other spaces of the diaspora in which Portuguese makes itself present to, dialogically, settle the definitions of the many Lusophonies we comprise.

Lusophony - a sum of distinctive senses based on a common denominator, which dichotomously splits into language and culture - it is not, as we already know, a concept without problems, especially when we move from the conceptual level to the concreteness of life. As Fiorin affirms (2010, p. 18), "one of the problems with supranational entities (in the case of Lusophony, the transnational entity is the CPLP) is that they are a juridical, political, economic, financial, and monetary space, but not an identity space". Therefore, it is not enough to simply think of a common supranational space without, however, negating it. And so, it is possible to propose Lusophony (and the identities which it may take on) as a contract in relation to the participating subjects (just as a nationality contract) in which part of the nationality is preserved, and, at the same time, a new "burden" of meaning coming from "other Lusophonies" is accrued. We will now discuss this aspect.

\footnotetext{
5 "Lusophony can be compared to a linguistic and, above all, cultural symbolic space in the realm of the Portuguese language and it's linguistic varieties that, at the geo-socio-political level, includes the countries that adopt Portuguese as their mother and official language (Portugal and Brazil), and official language (Angola, Cape Verde, Mozambique, Saint Thomas and Principe, and Guinea Bissau (...), and East Timor (equatorial Guinea must also be added to the list is countries within the officialdom of Portuguese). However, Lusophony cannot be restrained to what national frontiers delimit. In this conception of Lusophony, we must consider the many communities spread around the world that constitute the so called 'Luso-Diaspora' and the places that, while naming Portuguese as their language of use, in fact, use it minimally: Macau, Goa, Ceylon, Diu, Damão and Malacca. Besides that, Lusophony is inconceivable without the inclusion of Galicia" (Brito, 2010, p. 177).
} 


\section{IDENTITIES OF/IN LUSOPHONY}

And today I have already walked all the continents, but where I really like, the countries I like travelling to, I don't know if it is the force of the language, but it is to the lusophone countries. I see an identity among all of them. Martinho da Vila (Língua - vidas em Português, 2004)

Identity cannot be considered a natural and innate trait of the individual or collective. As Cunha (2012, p. 263) points to, it is necessary to note which are participating elements of the construction of identity at its different levels: the identity of the natural groups (such as the local family or community), the national identity (such as the imagined community), and the supranational identities that arise as a new format of personal fidelity. It is within these different levels that identities are found, at any moment, searching out legitimate definitions for its statute, but this search is almost always constructed from the idea of a unit of meaning ("the" nation, "the" language, "the" society, etc.), in other words, as an in-itself with a conscience of itself. Nonetheless, it is almost consensual to think that the notion of identity can no longer behave solely with the idea of a single unit of meaning: "the unit of identity is, therefore, utopic (made up or even paradoxical), since it is grounded, structured, and constructed based on the difference and the division in the pursuit of its entirety" (Brito, 2013, p. 23).

The construction of Lusophony, therefore, goes through the question of identity. Besides the belief of a lusophone identity based on the binomial language/culture, it is necessary to raise the question of identity in perspective: first, because it is not impervious and historically immutable; then, because the same person possesses different identities that superimpose each other without mandatorily excluding each other (familial, professional, local, age groups, national, and, maybe, supranational). As such, a man can be, simultaneously, paulistano (from the city of São Paulo), paulista (from the state of São Paulo, Brazilian, a doctor, someone's son, someone's husband, and lusophone. The simplicity of this example can help us to rethink the basis of construction for a lusophone identity.

If identity can be understood as a narrative of seeking, it will necessarily be seen through another's eyes (Brito, 2013, pp. 22-23). Thus, the construction of identity possesses a dimension that is more or less controlled by the individual, but always constrained by the recognition that one must make of another's identity, even if only to a certain degree of abstraction. Social identities have a symbolic structure historically constructed (as a certain national culture), a dimension defined by the imposition of an institutional organization that creates sense of objectivity (such as the word of the Church, of the State and of political parties) and an individual dimension, which can establish a tension between the imposed senses of objectivity of identity. For this reason, identity cannot take on only a resemblance (the very in-itself): it is necessary to also recognize the present differences in the identities that may change according to necessity and situation - in other words, "it is necessary for the individual to recognize himself as distinctive and, simultaneously, as immutable and continuous, regardless of eventual context variations" (Brito, 2013, p. 29). 
For Brito and Hanna (2010, p. 77), the "non-unification of identities is a fact that creates contradictions and discrepancies between the individual and collective levels to be mandatorily and recurrently negotiated". In this case, we focus, above all, on the issue of the negotiation of identities because this is the foundation to recognize the existence of multiple identities and their developmental logics. It would, therefore, be possible to suppose It would, therefore, be possible to suppose a manner of identity construction that privileges a greater mixture and that would be able to withstand a constant coexistence of similar and diverse elements, but not completely identical; we would have an identity grounded in heterogeneity and whose ties would be strong enough to reconcile the unity and diversity defended by various scholars.

To a certain degree, this is what some minority immigrant groups in Brazil accomplished. Japanese and Lebanese immigrants, for example, sought to mold their immigrant identity to the national Brazilian one that did not always accept them. Thus, in a constant negotiation of identity, these immigrants managed to demonstrate positive aspects of their presence to the Brazilian society. From that socio-historical situation in Brazil, we illustrate the concept of a hyphenated identity, according to American historian Jeffrey Lesser, who points out the fact that a hyphenated identity makes it possible for immigrants to use, in certain situations, their own original ethnic identity for their own purposes and, at other moments, to use their Brazilian identity to obtain the same advantages as other Brazilians. For Lesser (2001, p. 27),

the ethnicities brought and constructed by these immigrants were situational, and not "immutable primordial identities". In many moments, the immigrants and their descendants could embrace their "Niponicity" or their "Lebanicity", as well as their "Brazilinicity". Ethnicities many times crossed with nationalism (Brazilian or not), making those identities extremely flexible.

For this reason, it is common in Brazil to find use of expressions such as nipo-brasileiro (Japanese-Brazilian), sino-brasileiro (Chinese-Brazilian), líbano brasileiro (LebaneseBrazilian), and, more recently in the times of political correctness, afro-brasileiro (AfricanBrazilian). Applying this concept to the lusophone realm (and removing the etymological sense of reference to the "Luso" people, redefined for the matter of an identity brings us closer and distinguishes us), because of the existence of "hyphenated" lusophone identities, the following may be postulated: a luso-português [Luso-Portuguese], a luso-brasileiro [Luso-Brazilian], a Luso-Timorense [Luso-Timorese] (or the reverse of all of these) and so on, which would permit maintaining the national identity of each one and, simultaneously, adding on the transnational lusophone identity. These criteria could be used to name cultures as multiple or intertwined, just as it exists in relation to language varieties $^{6}$. In this sense, it is possible to be, simultaneously, singular and diverse in regards to

\footnotetext{
${ }^{6}$ There is thus a correlation between the notions of identity developed in this work and the variation and naming of the language, such as supranational (Portuguese language), national (Brazilian Portuguese, European Portuguese, Angolan Portuguese, Mozambican Portuguese, Portuguese from Azores, southern Portuguese) and local (Portuguese Carioca, Portuguese mineiro [from Minas Gerais], etc.) is equivalent to what was said in relation to a person identity.
} 
the mobility of identity that an individual is able to carry out depending on the situation (space) and moment (time) in which it is inserted, since a single individual or a single collective has fluid and mobile identities that can be recognized through different perspectives and, in this way, each present distinct definitions.

It is in this manner that, in a possible conception of Lusophony, amplifying the examples that may reinforce the concept of "integration between unity/variety" (Brito, 2013 , p. 59) should be sought out. A more practical solution for this might possibly be finding cases of "cultural meetings and interactions" (Brito \& Hanna, 2010, p. 83), both in traditional literature studies and in daily practices of the individuals who, effectively, give life to Lusophony. As such, in the context of lusophone globalization, each people cannot simply be a consumer of cultural products and senses, nor empty receptacles to be filled. They should, instead, be interpreter and producers of culture, be it from the outside, or stemming from a local tradition.

In the testimonials extracted from Língua - vidas em Português, selected for the following reflections, it is possible to identify a very significant kind of "social figure" in the passage from a local tradition to the space belonging to the other in which they are inserted, interpreting and giving (new) value to some traits of this new space of significance.

\section{MOVEMENT OF LUSOPHONE INDIVIDUALS IN THE LUSOPHONE SPACE}

We speak the same language, but it is not spoken the same way. When we communicate, we feel that; that desire for proximity and at the same time the distance that exists in our ways of being.

Teresa Salgueiro (Língua - vidas em Português, 2004)

Regardless of the apparent redundancy of the above subtitle, we see the need to specifically delimitate both the individuals who move about and the spaces through which they move. This is because the issue of immigration within the lusophone universe is extremely complex and, face with so many possibilities, we have restricted our interest and the focus given by the documentary in question. Thus, besides being conscious that lusophone immigrants are present in many non-lusophone countries, we have limited our considerations to those who transit through the lusophone countries because they are the ones responsible for the maintenance and variety of linguistic and cultural significations connected to the lusophone universe, to the specific culture of each of those immigrants and to the manner in which they are able to circulate those significations and construct new one from contact with other individuals.

These issues were raised by the documentary Língua - Vidas em Português (2004), directed by Victor Lopes, which presents a tableau of the presence of the Portuguese language in the world. In it a constant presence of the cultural and linguistic inheritance of the Portuguese colonizer can be seen, living together with the particular cultures of each space. Besides that, the movie reveals different accents that emerged from the contact with various languages and the use or the Portuguese language. Through these elements 
it is possible to reflect on the transformations of sense derived from the relation between the identity and the alterity of the common supranational lusophone space.

In this section, therefore, we will observe the different relationships from among Brazilians, Portuguese, Macanese, Angolan, Mozambican, Guinean, etc., who are found in their respective countries of origin or not and who have their own points of view and opinions captures by the director's camera.

The documentary permits the contemplation that the idea of an exchange of senses between individuals does not necessitate a common material and concrete space in order to put into practice an image of the same Lusophony. In the film, the notion of space is dilated by the cuts that introduce recorded scenes of distant spaces, which demonstrates a movement to surpass geopolitical limits of the national States. As such, a relationship and interaction between identities and alterities that alternate their statues according to adopted perspectives (global or local). In this case, the issue of identity is not taken in essential terms, for there is a situation in which each of the individuals are inserted. Thus, the fact of being an immigrant is merely contingent, which does not dispense us from thinking of the political and social dimensions of the individuals who participated in the documentary.

Another caveat is to the fact of our giving attention to the speech regarding the Portuguese language or the culture of each of the countries (or other member-countries of the CPLP) addressed by the personalities featured in the documentary (such as Mia Couto, José Saramago, João Ubaldo Ribeiro and Martinho da Vila) because we opted for the speech of those who posses little opportunities to express their worldviews and develop their points of view regarding subjects that concern them directly. Consequently, the focus is centered on the lusophone immigrants, that is, the immigrant whose origin and foreign experience occur within the lusophone geopolitical space.

Within that dynamic of exchange of senses among individuals and spaces, which determines them in a manner of identity (both at the material level and at the symbolic one), new senses are transported to other spaces, just as local senses re displaced by a new trait created by the presence of the alterity. For this reason, we see the lusophone universe represented in the documentary as an abstraction in which the intersubjective exchange of senses can lead us to a notion of Lusophony as a space of tension between innovation and tradition.

This opposition is based on the observations made by Brito (2010) that the elaboration of identity oscillates between the tradition/modernity and hybridism/mixture pairs. Besides that, these opposing pairs should be seen as inherent processes to the construction and negotiation of these very identities, because this is how it is possible to reflect on a modern tradition (and, maybe, on the opposite, a traditional modernity) in which the past mixes with the present, at the same time as it orientates and constructs a future in a universe of senses such as the lusophone one. It is this way that, hypothetically, we understand what one of the functions of lusophone immigrants might be: to establish connections between the different lusophone cultures, as a type of shapeless stitching of a patchwork quilt, possibly causing a certain strangeness in the variations and changes that such a contact might establish in the realm of the lusophone cultures. 
Thus, we comprehend this proposal as a solution for what Fiorin suggests about the basis of a community identity, based on politics, culture and language (2010, p. 27). There would be, therefore, a space for the articulation of diversity within a singular basis from which specific and unique senses of Lusophony could be recognized.

This would be, for example, the case of the student-couple Sofia Meireles and UIiengue Almeida. She from Mozambique, he from Angola and both students, in other words, three different identities are already present, a professional one and two connected to a geographical origin within the lusophone universe. At a specific moment in the documentary (6'45"), she states she likes the old town of Lisbon because it possesses a "village environment", in which people are closer to each other and know each other. That is how, therefore, she identifies a familiarity perceptive to her own history, while at the same time using those traces of proximal familiarity to qualify the space of which she is speaking, in order to, thus, distinguish it from other spaces which were traversed by her in the city.

Thus, although they are young immigrants (theoretically inserted in a great and global European city), they give (new) value to a historic Lisbon and not to modern and globalized place. Those same young people appear shortly later (9'07") walking through Porto and with a voiceover of José Saramago discussing Padre Vieira and the tradition of the word. By appreciating the past and the local, these youths represent a modernity that does not erase and exclude a place's characteristics (because they are not part of the totalizing globalization), while they concurrently do not lament the present surpassing the past, according to what Saramago states. For this reason, we gather that the young couple of this scene synthesizes the opposition between past and present, old and modern, central and peripheral, metropolitan and colonial, without, necessarily, excluding one hub to include the other. The conceptual opposition is in this way suspended or mixed in order to live a moment of the meeting if distinct identities, which can be composed, mutable, uncertain, and fluid whenever an adaptation to new situations that the host (not always positive) space provides is needed or desired.

Other young immigrants appear in another moment of the documentary, now all Angolan. Dilo Monteiro shows the Centro Comercial da Mouraria (commercial center of Mouraria), also in Lisbon, where there is a "crossing of various cultures" (his own words), mostly of Africans. The Guianese vender Fátima Embaló (from the Mercearia Africana [African General Grocery]) and the Macanese couple Dai Shaori and Liandi Xu, owners of a clothing store in the same location, all appear as well. The Centro Comercial could represent, for the documentary, a simulation of the lusophone space: a place of commerce that relies on the participation of individuals from different spaces within Lusophony, whose capacity for interaction and contact reveals the tolerance in relation to what is different and unexpected.

Next to Dilo Monteiro, two friends also narrate, separately, their situation. On the one hand, Jardel Vieira affirms that the Centro Comercial shows a great representative mixture of globalization through which Europe is going; on the other, André Mendes says that there is no difference between them and youth in France, China, and America 
because the likes and life projects are the same (perhaps a reflection of the standardization imposed by globalization). Finally, the conversation ends with Dilo Monteiro's observation that multiculturalism is a recent fact in Europe (at least at the moment in which his speech is recorded), but that it had already been present for a very long time in the old colonies. That opinion, to an extent, creates a certain neutralization of senses because it suspends the opposition between "there" (the ex-colony) and "here" (the exmetropolis). Thus, the point of view of these young immigrants and the way in which they reflect and articulate their discourse show a perception, above all, of a current experience regarding diversity in relation to the cultural practices and values integrated in the lusophone dynamic.

Dilo Monteiro also notes one of the most significant experiences in the documentary (at 38'10"). He often frequents Tia Alice's bar, a Portuguese singer of fado. Youth who represent the modern world and the multicultural experience show what is possible for multiculturalism, defended by their taking up and valuing a Lusitanian tradition represented by the fado sung by Tia Alice. It is within the space of the bar that the unity (which permits communication between young and old, immigrant and local that diversity (of the other's music, the other's experience) reconcile with each other to form an image of Lusophony that is, within its own limitations, lived and experience by different individuals. In this case, the opposition between local/traditional and exterior/modern is also suspended (such as in the earlier example of the couple). Thus, we observe that the lusophone being is not directly connected to a single nationality, nor does a single country possess a supremacy in saying what is or is not lusophone. Speaking Portuguese and being open to new experiences of meaning coming from others appears to be, for the documentary, some of the few characteristics needed to establish and maintain the existence of the lusophone universe.

From this scene, we can speculate on the social and linguistic practices of these immigrants. Here, the circulation within a cultural universe that is not one's own, from the historical and social point of view, leads to thinking that one of the ways a lusophone immigrant takes action is similar to that of a chameleon, as Landowski conceptualizes: as an individual who circulates, with certain ability, through two different universes of significance, that of one's origin and that of the host society. As such, the individual is able to take advantage of some benefits the host society may offer, but without losing the characteristics that differentiate he or she from that same society and that keep that individual in the status of immigrant, possessing a different speech pattern, way of viewing life, social values unique to his or her social group, specific tastes in music, food, among other habits.

It is, then, through these individuals common in their speech, behavior, reflections, passions, and desires that we broach a side of Lusophony very little spoken. Coming from the principal that for Lusophony to become a well-established, legitimate and rooted reality in the countries in which it should be present (at least in the formal and political levels), it is necessary that it be lived by all its citizens. Beyond that, even if this conciliation is not completely possible - because it creates the possibility of an unwanted 
homogeneity - what we consider fundamental for that virtual space is the coexistence and recognition of the different lives, as above illustrated.

It has to be noted that the common interest or the cultural value are negotiated in the interstices, place in which it is necessary to supplant narratives and essentialist subjectivities makes it so that the result of the social articulation of the different cultures is emphasized, attributing authority to the cultural hybridisms that emerge in moments of historical transformation (Brito \& Hanna, 2010, p. 85).

To understand how the identity dynamic is developed within the lusophone context, we return to the already mentioned hyphenated identity. Lesser, (2001), in studying the relations between immigrants and descendants of Asian origin in brazil, observed that they at time considered themselves Brazilian, at times recalled their identities of their countries of origin, according to how they wanted to demonstrate their supposed characteristics (such as, for example, a mathematical ability, which would be, thus, derived from a supposed Japanese trait, or an ease in social interactions, a Brazilian trait). There is a similar behavior from the immigrants in their relationships of approach and distancing concerning contact with other cultures. However, in contrast to the immigrants in Brazil, the differences between the lusophone immigrants in the Portuguese spaces are not as distant and the possibility of a mixture or "hyphenation" can become greater than what occurred in the Brazilian situation described by Lesser.

\section{LUSOPHONY, LUSOPHONIES, THIS ONE AND OTHER}

No Portuguese tongue there are tongues in Portuguese.

José Saramago (Língua - vidas em Português, 2004)

A possible solution for this identity dynamic, as Cunha points out (2012), is to view Lusophony as a weakened identity, but that is still capable of organizing a network of meanings of the lusophone subconscious. However, to this end, it is necessary to consider the identity narratives of each of the countries within the lusophone sphere, not so that they may be overcome or substituted, but so that they may intersect (the author calls this aspect the "meaning nodes", p. 269) in order to produce possible ramifications, resignifications and dialogues between tradition and modernity. It is at this moment that the idea of a hyphenated identity seems strengthen.

For this, we draw attention to Lourenço regarding the lusophone project: "if we want to give meaning to the lusophone galaxy, we must live it, as far as is possible, as inextricably Portuguese, Brazilian, Angolan, Mozambican, Cape-Verdean or San Tomean" (2001, p. 112). In addition, however, lusophone will only be a reality if the individuals live it within a single and, at the same time, local dimension of Lusophony and of each nationality. Living, therefore, with a sense of "village environment" (evoked in the documentary by the Mozambican Sofia) in any lusophone space, is how individuals will be able to treat each other equally, with the same common traits: 
for Lusophony to be a significant symbolic space for its inhabitants, it is necessary for it to be a space in which all linguistic variants be, respectfully, treated equally. (...) Evidently, lusophone origins are in Portugal and it is necessary to recognize that. Nonetheless, what is expected in the construction of the lusophone enunciative space is a community of equals, with the same origin. (Lourenço, 2001, p. 46)

Finally, what purpose does a fight for an equal, multi-sense and Portuguese-language-based Lusophony serve? So that, as the documentary reveals, it is possible to build more than bridges (which are constructed usually in a straight line and, at times, in only one direction), networks of signification, where the exchange of senses and values is tonic for a continuous and legitimate collective construction.

In effect, the documentary forges its main value based on its emphasis to diversity, whose existence is understood as a coexistence of opposites. Those are the traits and values that permit a thinking of lusophone based on a (hyphenated) diversity, without denying the existence of an oneness that unites us through history and that is fed by language. It is through this path that Lusophony, the Lusophonies, this one and the others can maintain and expand the senses of intimacy when faced by differences that do not separate, but that invite interaction, and whose traits should be institutionalized to the point of being recognized and conveyed by the spaces of the universe that is always under construction.

Translation: Gabriella da Silva Araújo

\section{REFERENCES}

Bauman, Z. (2000). Liquid modernity. Cambridge: Polity Press.

Brito, R. P. de (2010). Temas para a compreensão do atual quadro linguístico de Timor-Leste. In A. D. Pereira (Ed.), Ciências Q Letras - Ásia: história e cultura (vol. 48, pp. 175-194). Porto Alegre: Faculdade Portalegrense.

Brito, R. P. de (2013). Língua e identidade no universo da lusofonia: aspectos de Timor-Leste e Moçambique. São Paulo: Terracota.

Brito, R. P. de (2017). Entre vivências e estudos: por uma lusofonia possível. In A. M. Ferreira, C. Morais, M. F. Brasete \& R. L. Coimbra (Eds.), Pelos mares da língua portuguesa III (pp. 1043-1051). Aveiro: Universidade de Aveiro. Retrieved from http://hdl.handle.net/10773/18281.

Brito, R. P. de \& Hanna, V. (2010). Sobre identidade em contexto lusófono: reflexões. In N. B. Bastos (Ed.), Língua portuguesa: cultura e identidade nacional (pp. 75-88). São Paulo: IP-PUC-SP; EDUC.

Castells, M. (2010). The rise of the network society (vol. 1). Oxford: Blackwell.

Cunha, L. (2012). Singularidades inabaláveis e convergências desejadas: discursos e políticas da lusofonia. In N. Bastos (Ed.), Língua portuguesa: aspectos linguísticos, culturais e identitários (pp. 259-272). São Paulo: EDUC.

Harvey, D. (1989). The condition of Postmodernity. Oxford: Blackwell. 
Fiorin, J. L. (2011). Língua portuguesa, identidade nacional e lusofonia. In D. L. P. de Barros (Ed.), Preconceito e intolerância: reflexões linguístico-discursivas (pp. 119-135). São Paulo: Universidade Presbiteriana Mackenzie.

Landowski, Eric. (2002). Presenças do outro: ensaios de sociossemiótica II. São Paulo: Perspectiva.

Lesser, J. (1999). Negotiating national identities: immigrants, minorities and the Struggle for Ethnicity in Brazil. Durham: Duke University Press.

Lopes, V. (Director). (2004). Língua - vidas em Português [Film]. Brasil/Portugal: TV Zero/Costa do Castelo Filmes.

Lourenço, E. (2001). A nau de Ícaro. São Paulo, Brazil: Cia. das Letras.

Martins, M. de L. (2006). Lusofonia e luso-tropicalismo, equívocos e possibilidades de dois conceitos hiperidentitários. In N. Bastos (Ed.), Língua portuguesa: reflexões lusófonas (pp. 49-62). São Paulo: EDUC.

Woodward, K. (1997). Identity and difference. London: Sage.

\section{BIOGRAPHICAL NOTE}

Post-Doctorate from the University of Minho, PhD and Master Degree in Linguistics from the University of São Paulo. Professor and coordinator of the Lusophone Studies Centre of the Graduate Program in Humanities, Presbiteriana Mackenzie University. Coordinator of Programs and Projects of the Pró-Rectoría of UPM. Associate Researcher at the Centre for the Study of Portuguese-Speaking Literature at USP and Counselor at the National Institute of Linguistics of Timor-Leste. Coordinator of Portuguese language diffusion projects at Timor Lorosa'e National University in 2004 and 2012.

ORCID: https://orcid.org/o000-0002-0634-8572

Email: reginahelena.brito@mackenzie.br

Address: Presbiteriana Mackenzie University, Av. Brasil, 1220, Jd. Guanabara, Campinas, São Paulo, Brazil

* Submitted: 03.06.2018

* Accepted: 07.07.2018 